\title{
Biossegurança no trabalho em frigoríficos: da margem do lucro à margem da segurança
}

\author{
Biosafety of working in cold storage units: \\ from the profit margin to the safety margin
}

Gabriela Chaves Marra ${ }^{1}$

Luciana Hugue de Souza ${ }^{2}$

Telma Abdalla de Oliveira Cardoso ${ }^{1}$

\footnotetext{
${ }^{1}$ Escola Nacional de Saúde Pública Sérgio Arouca. Fundação Oswaldo Cruz. R. Leopoldo Bulhões 1480, Manguinhos. 21.041-210 Rio de Janeiro RJ Brasil. gabicmarra@uol.com.br ${ }^{2}$ Centro Universitário Dinâmica das Cataratas.
}

\begin{abstract}
The cold storage unit and meat production industry has made Brazil one of the leading suppliers and exporters of products of animal origin. The rapid expansion of the market has led to a rise in competitiveness from a capitalist standpoint, and in this respect corporate profit often leads to the need to adapt human actions to new functions in order to reduce costs and maximize production. These routine activities involve repetitive work, multi-tasking, long hours and operating machines with the use of sharp cutting tools, which is why the work is conducted wearing protective gear. Among the main hazards present, biological risks are the most important due to direct exposure to internal organs, blood, fecal matter, urine and placental or fetal fluids from slaughtered animals that may be infected with pathogens of zoonotic origin. This paper discusses the risks to which slaughterhouse-cold storage unit professionals are exposed, conducting a thorough bibliographical review of the literature that takes into consideration the conceptual framework of Biosafety, which contributes to improve the safety and health conditions of these workers.

Key words Slaughterhouses, Exposure to biological agents, Occupational hazards
\end{abstract}

Resumo A indústria frigorífica e o complexo de carnes fazem do Brasil um dos principais produtores e exportadores mundiais de produtos de origem animal. A ampliação do mercado leva à competitividade do ponto de vista capitalista e, nesta perspectiva, o lucro empresarial, muitas vezes impõe-se à necessidade de adaptar a ação humana às novas funções, procurando minimizar custos e maximizar produção. As atividades de rotina são longas, repetitivas, com acúmulo de tarefas, onde há operação de máquinas e utilização constante de instrumentos perfurocortantes, por isso, são realizadas com o uso de equipamentos de proteção. Dentre os agentes de risco de maior importância está o biológico, com a exposição por contato direto com sangue, vísceras, fezes, urina, secreções, restos placentários, líquidos e fetos, que podem estar infectados com patógenos de caráter zoonótico. Este artigo discute riscos a que estão sujeitos os profissionais de matadouros-frigoríficos, através de uma revisão integrativa da literatura, considerando o arcabouço conceitual da Biossegurança que contribui para a segurança e saúde dos trabalhadores.

Palavras-chave Matadouros, Exposição a agentes biológicos, Riscos ocupacionais 


\section{Introdução}

A indústria frigorífica e o complexo de carnes fazem hoje do Brasil um dos principais exportadores mundiais de produtos de origem animal. Segundo o Instituto Brasileiro de Geografia e Estatística (IBGE), em 2010 foram abatidos 29.265 milhões de bovinos, representando aumento de $4,3 \%$ em relação ao ano anterior ${ }^{1}$. Com relação ao abate de aves também houve elevação de 4,5\% na produção com relação à 2009, perfazendo 4.988 bilhões de unidades. O abate de suínos aumentou em 5,1\% com relação ao ano anterior com 32.510 milhões de unidades abatidas. O Brasil registrou, em 2010, exportações recordes no setor agropecuário com 76,4 bilhões de dólares, em comparação com 2009 (64,7 bilhões de dólares), cujo valor é $18 \%$ maior e supera em 4,6 bilhões de dólares os 71,8 bilhões de dólares registrados em 2008, até então o melhor ano para as vendas externas do agronegócio, segundo o Ministério da Agricultura Pecuária e Abastecimento².

A pressão exercida pelo mercado consumidor externo vem gerando uma expansão da produção e mantendo o Brasil entre os países com maiores taxas de exportação neste ramo.

Este resultado está sendo obtido gradativamente com o passar dos anos através de uma especialização produtiva, onde os métodos e as condições de trabalho encontrado nos estabelecimentos de produção de produtos de origem animal têm sofrido importantes modificações.

O segmento industrial para ser competitivo e alcançar a qualidade dos alimentos de origem animal, necessita cumprir as normas de inspeção e fiscalização sanitárias, assim deve investir continuamente no treinamento dos trabalhadores, manutenção preventiva de equipamentos e instalações, desde a fase de produção dos animais nas propriedades até a comercialização e a industrialização da carne. Para tanto o MAPA, através da Secretaria de Defesa Agropecuária elabora normas e procedimentos técnicos, realiza vigilância epidemiológica e sanitária dos rebanhos animais e assegura o padrão higiênico/sanitário dos produtos e subprodutos de origem animal destinados aos consumidores. Dentre estas normas está o Regulamento da Inspeção Industrial e Sanitária de Produtos de Origem Animal, que regulamenta para todo o território nacional as normas de inspeção industrial e sanitária dos produtos e subprodutos de origem animal ${ }^{3}$.

As indústrias de produção de alimentos de origem animal, para poderem exercer suas atividades no território brasileiro, precisam estar re- gistradas e sob inspeção do MAPA em suas instâncias federais, estaduais e municipais. Para tanto existe uma classificação dos estabelecimentos em: a) indústrias com Serviço de Inspeção Federal (SIF), quando realiza o comércio de seus produtos internacionalmente ou entre os Estados brasileiros; b) indústrias com Serviço de Inspeção Estadual (SIE), quando comercializa seus produtos dentro do Estado onde está localizado, e c) indústria com Serviço de Inspeção Municipal (SIM), quando realiza comercialização dentro dos limites do Município. Ressalta-se que apesar do tipo de inspeção determinar a abrangência de comercialização do produto, ela não determina a qualidade do mesmo. Portanto não há diferenças entre os SIF, SIE e SIM, no que se refere às normas de qualidade sanitária dos produtos para o consumo humano ${ }^{4}$.

Nas indústrias registradas com SIF, em função de exigências impostas pelo mercado consumidor importador e de atendimento às legislações específicas, as estruturas físicas das instalações, assim como o fluxo de produção e o controle de qualidade, são bem implantados, mantidos e supervisionados, já que deficiências nestes itens poderiam acarretar perdas comerciais importantes para as indústrias exportadoras.

Em contrapartida, em estabelecimentos menores como os abatedouros municipais (registrados com SIM), quando comparados aos estabelecimentos exportadores, fatores como o volume menor de negociações e a característica do mercado consumidor, tornam evidentes a existência de uma pressão para a diminuição dos custos de produção da indústria, influenciando as características do ambiente laboral dos trabalhadores.

Para qualquer tipo de indústria de produção de alimentos de origem animal, $\mathrm{o}$ acesso à matéria-prima em termos de quantidade e custo, é fundamental para o seu crescimento. Por sua vez, a sobrevivência desta indústria está condicionada à busca de eficiência operacional, da agregação de valor aos produtos garantindo qualidade e redução de custos no enfrentamento do mercado competitivo, entre outros fatores.

A ampliação do mercado de carnes, inclusive internacional, tem pressionado a chamada competitividade do ponto de vista capitalista e, nesta perspectiva, as atividades dentro das indústrias são intensificadas na busca de maior produtividade, o que resulta, segundo Marx ${ }^{5}$, em precarização das condições de vida e adoecimento dos trabalhadores e em aumento da acumulação de mais valia pela empresa. $\mathrm{O}$ aumento de produtividade gera maior jornada de trabalho, com ho- 
ras extras excessivas transformadas em rotina, ritmos exageradamente intensos, pressão e controle rigorosos sobre os trabalhadores ${ }^{6}$. Nestas condições, impõe-se a necessidade de adaptação das ações humanas às funções exigidas, objetivando sempre em minimizar custos e em maximizar a produção, ampliando, desta forma, o lucro das empresas ${ }^{7}$.

Antunes ${ }^{8}$ ressalta que o atual mundo do trabalho produz um quadro crítico que tem característica assemelhada em diversas partes do mundo, onde vigora a lógica do capital. A automação e a renovação dos equipamentos com a introdução da informatização e robotização; a modernização das plantas industriais; a redefinição organizacional da empresa com novas técnicas de gestão; o trabalho informal e o desemprego repercutem sobre os acidentes, as doenças do trabalho e os estilos de vida da população e evidenciam novas relações entre a política econômica e a saúde ${ }^{9}$. A insegurança por medo do desemprego faz com que as pessoas se submetam a regimes de trabalho intensos, em condições precárias, em ambientes insalubres e de alto risco, e a contratos com baixa remuneração. Sendo assim, o processo de trabalho e de produção estabelecidos, nos quais o homem participa como agente, podem compor-se em fatores determinantes para o desgaste da saúde deste trabalhador. Consequentemente, os padrões de morbimortalidade dos trabalhadores estão diretamente relacionados à maneira como estes estão inseridos nas formas de produção capitalista.

As atividades em matadouros-frigoríficos demandam do trabalhador atenção nas operações, que são em sua maioria manuais, rotineiras, fixas e pouco variáveis, em um intenso processo de produção, podendo gerar danos e acidentes, quando medidas preventivas não são adotadas ${ }^{10}$. Desta forma, analisar os riscos do trabalho nestes locais, para melhor compreender a inter-relação entre o trabalho, o processo saúde/doença do trabalhador e os fatores que o determinam, exigem a participação da Biossegurança como propositora de conhecimentos e formuladora de ações preventivas.

Este trabalho tem como objetivo discutir os riscos presentes, em especial o biológico, no ambiente laboral dos estabelecimentos de produção de produtos de origem animal, onde a busca por redução de custos influencia a forma com que o trabalho é prestado, a fim de evidenciar a necessidade da aplicação dos princípios de Biossegurança, para minimizar o adoecimento dos profissionais.

\section{Procedimentos metodológicos}

No tocante à tipologia relacionada ao objetivo, esta pesquisa consiste de um estudo exploratório. Gil ${ }^{11}$ destaca que a pesquisa exploratória é desenvolvida no sentido de proporcionar uma visão geral acerca de determinado fato, coloca o pesquisador em contato direto com tudo o que foi escrito, dito ou filmado sobre determinado assunto. "Dessa forma a mesma não é mera repetição do que já foi dito ou escrito sobre certo assunto, mas propicia o exame de um tema sob novo enfoque ou abordagem, chegando a conclusões inovadoras"12.

No que concerne aos procedimentos, referese a uma pesquisa bibliográfica, com abordagem qualitativa. Segundo Martins ${ }^{13}$, a pesquisa bibliográfica possibilita adquirir conhecimentos ou resolver um problema “... a partir de consultas a livros, artigos, (...). Tem como objetivo recolher, selecionar, analisar e interpretar as contribuições teóricas já existentes sobre determinado assunto". A abordagem qualitativa não procura enumerar e/ou mensurar os eventos estudados, nem utiliza instrumental estatístico na análise dos dados. Envolve a obtenção de dados descritivos sobre pessoas, lugares e processos interativos pelo contato direto do pesquisador com a situação estudada, buscando "compreender os fenômenos segundo a perspectiva dos sujeitos, ou seja, dos participantes da situação em estudo"14.

A coleta de dados envolveu a técnica de documentação indireta, particularmente dados de fontes secundárias, em razão da opção pela pesquisa bibliográfica. $\mathrm{Na}$ análise dos dados coletados optou-se pela técnica de análise qualitativa.

A pesquisa bibliográfica foi conduzida de acordo com os preceitos metodológicos da estatística descritiva, cujo objetivo é a leitura, a seleção e o registro de tópicos de interesse.

Para guiar a revisão, formulou-se a seguinte questão: quais são os principais riscos a que estão sujeitos os profissionais dos estabelecimentos de produção de produtos de origem animal e o que necessitam de aporte da Biossegurança?

Para a seleção dos artigos foram utilizadas as bases de dados: Literatura Latino-Americana e do Caribe em Ciências da Saúde (Lilacs); Medline/PubMed, da US National Library of MedicineNational Institutes of Health; BioMed Central e Scientific Electronic Library Online (SciELO).

A escolha das bases de dados deve-se ao fato delas conterem o maior número de periódicos indexados na área da saúde, o que possibilitou uma visão mais ampla das pesquisas realizadas 
sobre a temática em questão, disponibilizadas eletronicamente.

Como descritores foram utilizados aqueles empregados pelos Descritores em Ciências da Saúde (DeCS) da Biblioteca Virtual da Saúde (BVS) e os operadores boolianos OR e AND, resultados da seguinte combinação: "matadouros", "abatedouros", "riscos ocupacionais", "ambiente de trabalho", "condições de trabalho", "doenças profissionais" e "acidentes de trabalho". Na busca, os descritores foram utilizados em português, inglês e espanhol. Foi definido como intervalo para a busca o período de 2000 a 2011.

Os critérios de inclusão utilizados foram: os artigos cujas temáticas estão relacionadas à Biossegurança nas atividades laborais em estabelecimentos de produção de produtos de origem animal e disponibilizados na íntegra.

Como critério de exclusão adotou-se: artigos em idioma diferente do português, inglês ou espanhol, resumos, notas prévias, conteúdos de caráter geral e estudos que abordaram o tema Biossegurança, mas sem a especificidade de estabelecimentos de produção de produtos de origem animal.

Uma análise inicial foi realizada com base nos títulos dos manuscritos; nos resumos de todos os artigos que preenchiam os critérios de inclusão ou que não permitiam a certeza de que deveriam ser excluídos. Após análise dos resumos, todos os artigos selecionados foram obtidos na íntegra e posteriormente examinados de acordo com os critérios de inclusão estabelecidos. Em seguida, analisamos os diferentes contextos da temática à luz do referencial de Hinds et al. ${ }^{15}$ de modo que os artigos fossem integrados em subtemas, conforme a perspectiva conceitual de cada contexto, de forma a atingir o objetivo deste estudo, evidenciando a necessidade da aplicação dos princípios de Biossegurança para minimizar o adoecimento dos profissionais e o risco de acidentes.

\section{Resultados e discussão}

Dentre os 289 estudos identificados, foram eliminados 205 por não atenderem aos critérios de inclusão (190) e por repetição (15). Após a leitura dos 84 estudos restantes, foi feito um grupamento, por similaridade e pertinência aos subtemas a serem discutidos.

\section{Riscos ocupacionais}

A busca do conhecimento a respeito do processo saúde-doença que se sobrepõe aos trabalhadores e que culminam na ocorrência de doenças ocupacionais ou de acidentes de trabalho leva ao estudo dos fatores de risco a que estão sujeitos.

Pereira ${ }^{16}$ destaca que o "fator de risco" acompanha um aumento de probabilidade de ocorrência do agravo à saúde, sem que o referido fator tenha que interferir, necessariamente, em sua causalidade.

Em 1977, a Organização Mundial da Saúde (OMS) reforçou a necessidade de maior atenção ao problema da saúde dos trabalhadores, com destaque para os programas de higiene no trabalho, promoção e manutenção da saúde do trabalhador. Nessa ocasião, classificou os riscos ocupacionais em biológicos, físicos, químicos, ergonômicos e psicossociais ${ }^{17}$.

No Brasil, a criação da Fundação Jorge Duprat Figueiredo de Segurança e Medicina do Trabalho (Fundacentro), em 1966, marca o início da preocupação do governo com os altos índices de acidentes e com as doenças do trabalho. $\mathrm{Na}$ legislação, expressou-se pela consolidação das Leis do Trabalho (CLT), composta por uma série de Normas Regulamentadoras (NR) relativas à segurança e medicina do trabalho, aprovadas pela Portaria n 3.214 , de $1978^{18}$.

Os trabalhadores dos estabelecimentos de produção de produtos de origem animal, tais como abatedor, desossador, magarefe e retalhador de carne, assim como os profissionais da limpeza e da manutenção, são contratados pelo regime celetista trabalhista, ou seja, regidos pela CLT. Desse modo, a empresa deve cumprir o que está estabelecido nas NR, como por exemplo, a obrigatoriedade de constituir a Comissão Interna de Prevenção de Acidentes (CIPA) (NR5), identificar as atividades ou operações insalubres que se desenvolvem acima dos limites de tolerância estabelecidos (NR15), elaboração e implementação do Programa de Prevenção de Riscos Ambientais (PPRA) (NR9) a fim de identificar e avaliar os riscos ambientais existentes e consequente controle de sua ocorrência.

Os estabelecimentos de produção de produtos de origem animal são unidades industriais compostas por ambientes que podem propiciar aos trabalhadores a exposição a diferentes tipos de riscos, os quais podem acarretar agravos à saúde. Dentre os artigos identificados por esta pesquisa, $32,1 \%$ (27) abordaram o tema de riscos ocupacionais dentro desses espaços laborais. 
Os matadouros-frigoríficos são locais úmidos, com um nível amplificado de ruído, onde há uma alternância de temperaturas altas e baixas. As operações de abate ocorrem de forma sequencial, como em uma indústria de montagem de carros, na qual a velocidade de trabalho é determinada pelo número de animais que devem ser abatidos por intervalo de tempo ${ }^{19}$. A análise da rotina de trabalho nestes estabelecimentos demonstra a complexidade dos riscos a que estão sujeitos os trabalhadores durante sua jornada de trabalho, em todas as etapas do fluxograma de abate, desde a recepção dos animais até a expedição dos produtos (Quadro 1).

Este quadro revela uma força de trabalho exposta a uma série de riscos ambientais que podem gerar problemas de saúde de caráter físico e psíquico, destacando-se os cortes, as lesões por esforços repetitivos, a depressão, a angústia, o estresse, a contaminação por agentes biológicos, dentre outros.

\section{Riscos que podem gerar transtornos no quadro de saúde dos trabalhadores}

Várias pesquisas demonstraram que, apesar do aumento dos postos de trabalho devido à expansão do setor, houve uma precarização nas condições laborais: expressiva rotatividade nos postos; diminuição do salário de admissão, apesar do aumento da escolaridade dos trabalhadores. Relatam também que há um expressivo aumento no número de casos de acidentes e de adoecimento em função da agressiva investida do setor no aumento da produtividade ${ }^{20-24}$.

O Ministério do Trabalho e Emprego ${ }^{25}$ relata que os processos de produção utilizados nas empresas de abate e processamento de carnes são organizados de tal maneira que as atividades desenvolvidas apresentam potencial risco à saúde e à segurança dos trabalhadores. Dentre os diferentes tipos de risco ocupacional a que estão sujeitos os trabalhadores, destacam-se:

. Risco químico - produtos químicos utilizados na higienização dos locais de abate e dos equipamentos; produtos e processos químicos utilizados para a produção da carne, como a salga e a defumação.

- Risco de acidentes - devido ao manuseio de equipamentos perfurocortantes utilizados no abate e cortes da carne; eletricidade; quedas.

- Risco ergonômico - devido ao ritmo excessivo de trabalho, repetitividade das tarefas, levantamento de pesos e posturas inadequadas no trabalho.
- Risco físico - devido às vibrações do maquinário, variações bruscas de temperatura pela entrada e saída de câmaras frias, umidade constante e equipamentos de escaldadura, com água à alta temperatura.

- Risco biológico - devido à exposição aos agentes biológicos como: bactérias, vírus, fungos, parasitas, dentre outros.

O Quadro 2 apresenta a descrição dos principais problemas que podem afetar estes profissionais.

É importante ressaltar o esforço e a força que os profissionais empregam para executar as atividades rotineiras, no manuseio de produtos e/ ou no uso de ferramentas. Este esforço depende da posição do objeto em relação ao corpo. O manuseio de produtos ou equipamentos, mesmo de peso leve, pode exigir esforços respeitáveis, o que gera uma alta prevalência de distúrbios osteomusculares relacionados ao trabalho (DORT) $)^{16,21,26-29}$. Este esforço exercido pelas mãos e articulações dos trabalhadores é ainda ampliado pelo uso de luvas, repetitividade de movimentos e pela resistência dos produtos manuseados quando estão sob temperaturas baixas. Ressalta-se que estas podem contribuir também para a incidência de acidentes, uma vez que reduzem a sensibilidade táctil e diminuem a destreza manual.

A manipulação de material perfurocortante é o agente de risco de acidente de maior importância neste tipo de trabalho. Vasconcellos et al.. ${ }^{21}$, em um estudo entre trabalhadores da indústria frigorífica, no estado de Mato Grosso, no período de 2000 a 2005, apontam a faca como o instrumento responsável por $43,3 \%$ dos acidentes de trabalho registrados. Estes autores destacam ainda que o setor ocupou a segunda posição em notificação de acidentes de trabalho registrados pelas Comunicações de Acidentes de Trabalho (CAT), representando $10 \%$ de todos os casos no período.

\section{Risco biológico}

Durante todo o processo de abate os trabalhadores estão em contato direto com: sangue, vísceras, fezes, urina, secreções vaginais ou uterinas, restos placentários, líquidos e fetos de animais; e por esta razão, o risco biológico se torna uma das maiores preocupações, considerando a abrangência rotineira da exposição e o caráter zoonótico das doenças que podem afetar os animais.

Dentre os 84 estudos identificados na pesquisa, $54(64,3 \%)$ abordam diversas doenças infec- 
Quadro 1. Riscos ocupacionais na sequência das operações de abate.

\begin{tabular}{|c|c|}
\hline $\begin{array}{l}\text { Etapa do processo } \\
\text { de abate }\end{array}$ & Riscos \\
\hline $\begin{array}{l}\text { Recepção e condução } \\
\text { dos animais }\end{array}$ & $\begin{array}{l}\text { Reação do animal - coice, chifrada, cabeçada, esforço físico intenso, contato } \\
\text { com fezes e urina }\end{array}$ \\
\hline $\begin{array}{l}\text { Inconsciência/ } \\
\text { atordoamento e } \\
\text { insensibilização } \\
\text { (pistola pneumática, } \\
\text { descarga elétrica) }\end{array}$ & $\begin{array}{l}\text { Stress pela atividade, manuseio de arma, eletricidade, repetitividade, postura } \\
\text { inadequada, contato com fezes, urina e vomito, ruído intenso }\end{array}$ \\
\hline Sangria & $\begin{array}{l}\text { Contato com sangue, inalação de aerossóis, stress pela atividade, monotonia, } \\
\text { repetitividade, aplicação de força, queda do animal, manipulação de material } \\
\text { perfurocortante (faca), ruído intenso, piso escorregadio }\end{array}$ \\
\hline $\begin{array}{l}\text { Levantamento e } \\
\text { escalda dos animais } \\
\text { Esfola (retirada do } \\
\text { couro, cascos e } \\
\text { chifres) } \\
\text { Evisceração } \\
\text { Remoção e inspeção } \\
\text { da cabeça }\end{array}$ & $\begin{array}{l}\text { Contato com fezes e sangue, inalação de aerossóis, manipulação de material } \\
\text { perfurocortante (faca e ganchos), monotonia, repetitividade, hipersolicitação } \\
\text { anatômica e/ou funcional das articulações, em posições extremas, vibrações, } \\
\text { aplicação de força, queda do animal, eletricidade, ruído intenso, pressa pela } \\
\text { velocidade da linha de produção, temperatura e umidade excessivas, piso } \\
\text { escorregadio }\end{array}$ \\
\hline $\begin{array}{l}\text { Remoção e inspeção } \\
\text { das vísceras }\end{array}$ & $\begin{array}{l}\text { Contato com fezes, sangue e órgãos, inalação de aerossóis, queda de peças dos } \\
\text { animais (órgãos), manipulação de material perfurocortante (faca), monotonia, } \\
\text { repetitividade, hipersolicitação anatômica e/ou funcional das articulações, } \\
\text { aplicação de força, eletricidade, ruído intenso, pressa pela velocidade da linha de } \\
\text { produção, temperatura e umidade excessivas, piso escorregadio. }\end{array}$ \\
\hline $\begin{array}{l}\text { Corte para divisão da } \\
\text { carcaça e lavagem das } \\
\text { meias carcaças }\end{array}$ & $\begin{array}{l}\text { Manipulação de material perfurocortante (faca e moto-serra), monotonia, } \\
\text { repetitividade, hipersolicitação anatômica e/ou funcional das articulações, em } \\
\text { posições extremas, vibrações, aplicação de força, eletricidade, ruído intenso, } \\
\text { pressa pela velocidade da linha de produção, contato constante com água fria sob } \\
\text { pressão, temperatura e umidade excessivas, piso escorregadio. }\end{array}$ \\
\hline Desossa & $\begin{array}{l}\text { Manipulação de material perfurocortante (faca e fragmentos de ossos), } \\
\text { repetitividade, monotonia, hipersolicitação anatômica e/ou funcional das } \\
\text { articulações, em posições extremas, vibrações, aplicação de força, ruído intenso, } \\
\text { pressa pela velocidade da linha de produção, temperatura e umidade excessivas, } \\
\text { piso escorregadio. }\end{array}$ \\
\hline $\begin{array}{l}\text { Resfriamento e } \\
\text { armazenamento }\end{array}$ & $\begin{array}{l}\text { Manipulação de material perfurocortante (ganchos, fragmentos ósseos), } \\
\text { vibrações, aplicação de força, eletricidade, ruído intenso, pressa pela velocidade da } \\
\text { linha de produção, temperatura excessiva, piso escorregadio. }\end{array}$ \\
\hline $\begin{array}{l}\text { Bucharia e triparia } \\
\text { (cozimento do } \\
\text { estomago e lavagem } \\
\text { dos intestinos) }\end{array}$ & $\begin{array}{l}\text { Contato com fezes, sangue e órgãos, produtos químicos, manipulação de material } \\
\text { perfurocortante (faca), monotonia, repetitividade, eletricidade, ruído intenso, } \\
\text { pressa pela velocidade da linha de produção, temperatura e umidade excessivas, } \\
\text { piso escorregadio. }\end{array}$ \\
\hline $\begin{array}{l}\text { Graxaria (produção } \\
\text { de farinha de osso e } \\
\text { carne para ração } \\
\text { animal) }\end{array}$ & $\begin{array}{l}\text { Contato com fezes, sangue e órgãos, produtos químicos, manipulação de material } \\
\text { perfurocortante (faca, fragmentos ósseos, dentes), repetitividade, aplicação de } \\
\text { força, eletricidade, ruído intenso, produtos químicos, temperatura e umidade } \\
\text { excessivas, piso escorregadio. }\end{array}$ \\
\hline
\end{tabular}

Fonte: Tavolaro et al. ${ }^{19}$; Johnson et al. ${ }^{20}$; Vasconcellos et al. ${ }^{21}$; Gomaa et al..$^{22}$; Hinrichsen ${ }^{23}$; Sarda et al. ${ }^{24}$; Serranheira et al..$^{27}$; Johnson e Ndetan ${ }^{30}$; Lachance et al. ${ }^{31}$; Pacheco e Yamanaka ${ }^{32}$; Netto e Johnson ${ }^{33}$. 
ciosas, subtema relacionado ao risco biológico (Tabela 1).
Os agentes etiológicos são classificados em quatro segundo as classes de risco, tendo como

Quadro 2. Principais problemas que podem afetar os profissionais dos estabelecimentos de produção de produtos de origem animal, segundo estudos publicados de 2000 a 2011.

\begin{tabular}{|c|c|c|}
\hline \multicolumn{2}{|r|}{ Problema } & Número da referência \\
\hline Acidentes & $\begin{array}{l}\text { Perfurocortantes } \\
\text { Cortes ocasionados por facas } \\
\text { Perfuração por fragmentos ósseos } \\
\text { Acidentes com pistola pneumática }\end{array}$ & $\begin{array}{l}18,25,26,28,29,31 \\
34,35\end{array}$ \\
\hline $\begin{array}{l}\text { Problemas } \\
\text { psicossociais }\end{array}$ & $\begin{array}{l}\text { Stress } \\
\text { Uso de drogas, álcool e alteração no comportamento }\end{array}$ & $18,23,32,34,36,37$ \\
\hline $\begin{array}{l}\text { Problemas } \\
\text { músculo- } \\
\text { esqueléticos }\end{array}$ & $\begin{array}{l}\text { Lesões por esforço repetitivo; epicondilite; dor, } \\
\text { parestesia e problemas articulares; lesões dos nervos } \\
\text { ulnar e radial, artrite, artrose, reumatismo, espondilose }\end{array}$ & $\begin{array}{l}18,23,26,27,28,32 \\
34,37\end{array}$ \\
\hline $\begin{array}{l}\text { Problemas nas vias } \\
\text { respiratórias }\end{array}$ & $\begin{array}{l}\text { Gripes, amidalite, laringite, bronquite, } \\
\text { broncopneumonias, pneumonias, rinite, asma dentre } \\
\text { outros }\end{array}$ & $18,19,27,28,34,38,39$ \\
\hline Risco químico & Intoxicação, atordoamento & $21,27,38,39,40$ \\
\hline Outros problemas & $\begin{array}{l}\text { Lesões dos tecidos e da pele ou necrose (frostbite) } \\
\text { causadas pelo frio } \\
\text { Risco aumentado de câncer }\end{array}$ & $\begin{array}{l}18,28,34 \\
18,19,41,42,43,44,45\end{array}$ \\
\hline
\end{tabular}

Tabela 1. Distribuição dos artigos por tipo e classe de risco do agente etiológico causador da doença.

\begin{tabular}{lll}
\hline & Patógeno & \multicolumn{1}{c}{ Número de referência do artigo } \\
\hline Brucella & 3 & $19,46,47,48,49,50,51,52,53,54,55,56$ \\
Leptospira & 2 & $52,57,58,59,60,61,62$ \\
Toxoplasma gondii & 2 & $52,61,63,64,65,66$ \\
Coxiella burnetii & 3 & $67,68,69,70$ \\
Streptococcus & 2 & $71,72,73,74$ \\
Campylobacter & 2 & $75,76,77$ \\
Virus hepatite E & 2 & $78,79,80$ \\
Salmonella & 2 & 78,80 \\
Taenia solium & 2 & 81,82 \\
Virus Nipah & 3 & 83,84 \\
Virus hepatite B & 2 & 85 \\
Mycobacterium bovis & 3 & 86 \\
Trichophyton verrucosum & 2 & 87 \\
Trichinella & 2 & 88 \\
Virus Crimean-Congo Hemorrhagic fever & 4 & 89 \\
Cryptosporidium & 2 & 90 \\
Prion causador da doença de Creutzfeldt-Jakob & 2 & 91 \\
Babesia & 2 & 92 \\
Toxocara & 2 & 93 \\
\hline
\end{tabular}


base vários critérios, dos quais destacam-se: a gravidade da infecção que causa, a virulência, a patogenicidade, a dose infectante, o modo de transmissão, a estabilidade do agente, a concentração e o volume, a origem do material patogênico, a disponibilidade de medidas profiláticas e de tratamento eficaz, a resistência a drogas, a endemicidade e a capacidade de disseminação no meio ambiente ${ }^{92}$. A importância desta classificação está centrada nos aspectos relacionados à determinação de medidas a serem tomadas para a contenção e o controle dos riscos relaciona$\operatorname{dos}^{94}$. A classe 1 é a de menor risco e a classe 4 a de maior. O Gráfico 1 apresenta a distribuição das classes de risco dos agentes etiológicos causadores das doenças infecciosas abordadas nos artigos identificados neste estudo.

a) Doenças causadas por agentes biológicos da classe de risco 4

São agentes que representam sério risco para o homem e para os animais, provocam doenças fatais, além de apresentarem um elevado potencial de transmissão por aerossóis. Até o momento não há medidas profiláticas ou terapêuticas eficazes para infecções adquiridas.

Foi encontrado 1 artigo que discute a febre hemorrágica causada por um nairovirus, Crimean Congo Hemorrhagic Fever Vírus. Williams et al. ${ }^{88}$ demonstram a soroconversão de $30 \%$ dos profissionais que lidavam diretamente com o abate de animais e o processamento de carnes.

b) Doenças causadas por agentes da classe de risco 3

O patógeno pode provocar infecções graves no homem e nos animais, podendo propagar-se de indivíduo para indivíduo através de aerossóis,

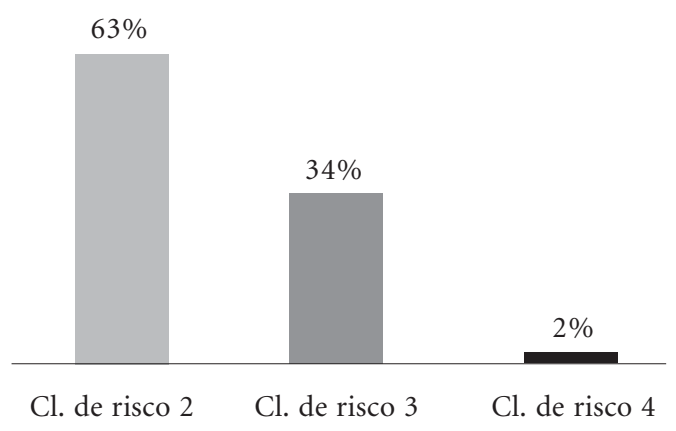

Gráfico 1. Classe de risco dos agentes etiológicos causadores de doenças infecciosas. pelas vias respiratórias. Dentre os 54 artigos identificados, que abordam aspectos de algumas das doenças infecciosas ocupacionais para os trabalhadores dos estabelecimentos de produção de produtos de origem animal, 19 possuem os agentes etiológicos da classe de risco 3.

A brucelose foi a doença ocupacional mais representativa, tendo sido identificados 12 estudos $(22,2 \%)$ entre os artigos analisados. Este dado corresponde ao que é relatado pela literatura, ou seja, de que a brucelose no homem é principalmente de caráter profissional (tratadores, proprietários, médicos veterinários) ou aqueles que trabalham com produtos de origem animal (matadouros, laboratoristas) $)^{91,92}$.

Também foram encontrados artigos de doenças causadas por outros agentes etiológicos pertencentes à classe de risco 3. 7,4\% (4) dos artigos foram sobre Coxiella burnetii, demonstrando que é um agente que possui um risco representativo entre os profissionais de matadouros e de frigoríficos. Acha e Szyfres ${ }^{95}$ relatam uma epidemia ocorrida no Uruguai em uma indústria frigorífica, em 1976, que acometeu um total de 310, dos 630 operários e de inspeção sanitária e, ao final, estabeleceram como as maiores fontes de contágio, os aerossóis contaminados, ocasionados pela manipulação de placentas e de líquido amniótico. Além disto, determinaram que estes profissionais estão entre os mais susceptíveis a contrair ocupacionalmente a febre Q.

Os aerossóis são partículas de tamanho que pode variar de 0,001 a $100 \mathrm{~mm}$, sólidas e líquidas, suspensas em um gás, geralmente o oxigênio, que podem permanecer em suspensão por várias horas $^{96}$. Os aerossóis infectantes podem ser gerados pela manipulação de materiais biológicos e pela utilização incorreta de alguns equipamentos, como centrífugas e homogenizadores. Via de regra, a rota de maior risco, nas infecções acidentais, é aquela causada pelas partículas contaminadas transportadas pelo ar ${ }^{97}$. É o modo de transmissão de maior dificuldade de prevenção e, assim, em determinadas atividades, a utilização de proteção respiratória é obrigatória.

A encefalite ou pneumonia causada pelo Vírus Nipah representa 3,7\% (2) dos artigos. Sahani et al. ${ }^{98}$ e Chew et al. ${ }^{83}$ relatam surtos de encefalite e de pneumonia ocorridas na Malásia nos anos de 1998 e 1999, onde houve o contágio de pessoas, cães e gatos por carne de suínos infectados. Entre as pessoas afetadas haviam cinco trabalhadores de matadouros. O estudo demonstrou uma taxa de soroconversão de 4,8\% entre os trabalhadores de abatedouros de suínos. Su- 
gerem ao final a necessidade da utilização de equipamentos de proteção individual e um controle rígido através da vigilância de infecções pelo vírus nas granjas produtoras, uma vez que a detecção do vírus no matadouro é muito difícil.

Biffa et al. ${ }^{85}$ relatam que os trabalhadores dos estabelecimentos de produção de produtos de origem animal estão entre as classes profissionais mais susceptíveis à doença, pela exposição aos aerossóis provenientes de bovinos infectados. Apesar da tuberculose causada pelo M. bovis ser uma doença zoonótica importante, ela só representou 1,9\% (1) dos artigos encontrados. Porém, ressalta-se que existe uma estimativa de que aproximadamente $3 \%$ dos casos de tuberculose e $17,2 \%$ de linfadenite cervical em humanos são devidos ao $M$. bovis ${ }^{84}$.

c) Doenças causadas por agentes da classe de risco 2

Os agentes da classe de risco 2 podem provocar infecções no homem ou nos animais, porém possui potencial de propagação limitado e dispõe-se de medidas terapêuticas e profiláticas eficientes. Nesta classe de risco estão os agentes etiológicos de aproximadamente $72 \%$ das patologias identificadas no Brasil ${ }^{99}$.

Este estudo identificou 35 artigos entre os 54 estudos sobre doenças infecciosas ocupacionais entre os trabalhadores de matadouros, cujos agentes etiológicos são pertencentes à classe de risco 2. Entre eles, a lepstospirose foi a doença ocupacional mais relatada (13\%), como particularmente perigosa aos profissionais de matadouros, médicos veterinários, trabalhadores de arrozais, canaviais, minas, esgotos e militares. Isto se deve à possibilidade de exposição à água contaminada com urina de animais infectados. Causada pela Leptospira interrogans, pode surgir esporadicamente ou em surtos epidêmicos. Outro patógeno relatado com mais frequência foi o Toxoplasma gondii $(11,1 \%)$. Apesar dos bovinos serem considerados hospedeiros mais resistentes ao $T$. gondii, houve relatos de alta prevalência de reagentes em bovinos e em funcionários de matadouros e frigoríficos.

Outros patógenos levantados com menor frequência foram: Streptococcus $(7,4 \%)$, Campylobacter $(5,6 \%)$, Virus da hepatite E (5,6\%), Salmonella $(3,7 \%)$, Taenia solium $(3,7 \%)$ e Virus hepatitis B, Trichophyton verrucosum, Trichinella, Cryptosporidium Babesia e Toxocara com 01 artigo $(1,9 \%)$ cada.

\section{Considerações finais}

A ampliação do mercado de carnes tem pressionado a chamada competitividade do ponto de vista capitalista e, nesta perspectiva, o lucro empresarial, muitas vezes, se impinge em detrimento da saúde dos trabalhadores. As exigências para o aumento de produtividade, traduzidas na ampliação da jornada de trabalho, ritmo de trabalho, pressão e controle rigorosos, impõem aos trabalhadores uma adaptação às funções requeridas. Os processos de produção utilizados nas empresas de abate e processamento de carnes estão organizados de tal maneira que as atividades de trabalho desenvolvidas apresentam potencial risco à saúde e à segurança dos trabalhadores.

A prevenção é a melhor maneira de se evitar qualquer tipo de acidente ou de adoecimento no trabalho. A identificação e a compreensão dos riscos a que estão sujeitos os profissionais de matadouros-frigoríficos é uma abordagem de relevância para a saúde ocupacional destes profissionais, uma vez que elenca os problemas a serem discutidos, tornando-se o passo inicial para resolvê-los. Bem como o mapeamento e identificação dos riscos, um sistema de vigilância em saúde; utilização de equipamentos de segurança, de proteção individual e de proteção coletivos; treinamento dos trabalhadores, com relação à atividade, higiene pessoal e riscos são essenciais para a prevenção e a diminuição do número de acidentes e patologias associadas a estes riscos. Todos estes elementos fazem parte de um programa de Biossegurança, de atuação transdisciplinar, que somente com a sua aplicação é possível estabelecer medidas eficazes de prevenção, a fim de reduzir os custos associados ao absenteísmo e ao tratamento dos trabalhadores que adoecem, o sofrimento e a incapacidade que podem gerar.

Torna-se urgente identificar a dimensão do problema nas indústrias brasileiras e desenvolver programas de Biossegurança, no sentido de prevenir os riscos presentes. 


\section{Colaboradores}

GC Marra e TAO Cardoso trabalharam na concepção e no delineamento do estudo, na pesquisa e no levantamento de material bibliográfico, na análise dos dados, na redação e revisão crítica do artigo e na aprovação de sua versão final. LH Souza trabalhou no delineamento do estudo, na análise dos dados, na redação e revisão crítica do artigo e na aprovação de sua versão final.

\section{Referências}

1. Brasil. Instituto Brasileiro de Geografia e Estatística (IBGE). Estatísticas da Produção Pecuária. [base de dados na Internet] 2010. [acessado $2010 \mathrm{dez} 3$ ]. Disponível em: http://www.ibge.gov.br/home/estatistica/ indicadores/agropecuaria/producaoagropecuaria/ default.shtm

2. Brasil. Ministério da Agricultura, Pecuária e Abastecimento. Balança Comercial, 2011. [página na internet] 2011. [acessado $2011 \mathrm{dez} 9$ ]. Disponível em: http://www.agricultura.gov.br/cooperativismo-associativismo/noticias/2011/01/exportacoes-batem-uss76-bi-e-alcancam-maior-valor-da-historia.

3. Brasil. Ministério da Agricultura Pecuária e Abastecimento. Decreto 30.691, de 29 de março de 1952. Diário Oficial da União 1952; mar 6.

4. Figueiredo EAP, Schmidt GS, Avila VS, Jaenisch FRF, Paiva DP. Recomendações técnicas para a produção, abate, processamento e comercialização de frangos de corte coloniais. Embrapa Suínos e Aves. Sistemas de Produção. 2007. [acessado 2012 jan 30]. Disponível em: http://sistemasdeproducao.cnptia. embrapa.br/FontesHTML/Ave/SistemaProducaoFrangosCorteColoniais/preparo.htm

5. Marx K. O Capital. Livro I. São Paulo: Nova Cultural; 1996. (Coleção Os Economistas)

6. Cañete I. Humanização: Desafio da Empresa Moderna, a ginástica laboral como um caminho. São Paulo: Ícone; 2001.

7. Franco T, Druck G. Padrões e industrialização, riscos e meio ambiente. Cien Saude Colet 1998; 3(2):6172.

8. Antunes R. Trabalho e precarização numa ordem neoliberal. In: Gentili P, Frigotto G, organizadores. A Cidadania negada: políticas de exclusão na educação e no trabalho. São Paulo: Cortez; 2001. p. 35-48.

9. Wünch Filho V. Variações e tendências na morbimortalidade dos trabalhadores. In: Monteiro CA, organizador. Velhos e novos males da saúde no Brasil: a evolução do país e suas doenças. São Paulo: Hucitec, Nupens, USP; 1995. p. 289-330.

10. Vilela RAG, Almeida IM, Mendes RWB. Da vigilância para prevenção de acidentes de trabalho: contribuição da ergonomia da atividade. Cien Saude Colet 2012; 17(10):2817-2830.

11. Gil AC. Métodos e técnicas de pesquisa social. São Paulo: Atlas; 1999.

12. Lakatos MA, Marconi EM. Fundamentos de metodologia científica. São Paulo: Atlas; 2003.

13. Martins GA. Manual para elaboração de monografias: trabalhos acadêmicos, projetos de pesquisa, relatórios de pesquisa, dissertações, 50 resumos de dissertações. São Paulo: Atlas; 1990.

14. Godoy AS. Introdução à pesquisa qualitativa e suas possibilidades. Rev Administração de Empresas 1995; 35(2):57-63.

15. Hinds PS, Chaves DE, Cypress SM. Context as a source meaning and understanding. Qual Health Res 1992; 2(1):61-74.

16. Pereira MG. Epidemiologia: teoria e prática. Rio de Janeiro: Guanabara Koogan; 1995. 
17. Organización Mundial de la Salud (OMS). Métodos utilizados para estabelecer niveles admisibles de exposición profesional a los agentes nocivos. Genebra: OMS; 1977.

18. Brasil. Ministério do Trabalho e Emprego (MTE). Portaria $n^{\circ} 3.214$, de 8 de junho de 1978. Aprova as Normas Regulamentadoras - NR - do Capítulo V, Título II, da Consolidação das Leis do Trabalho, relativas a Segurança e Medicina do Trabalho. Diário Oficial da União 1978; 6 jul.

19. Tavolaro P, Bicudo Pereira IMT, Pelicioni MCF, Oliveira CAF. Empowerment como forma de prevenção de problemas de saúde em trabalhadores de abatedouros. Rev Saude Publica 2007; 41(2):307-312.

20. Johnson ES, Ndetan H, Felini MJ, Faramawi MF Singh KP, Choi KM, Qualls-Hampton R. Mortality in workers employed in pig abattoirs and processing plants. Environ Res 2011; 111(6):871-876.

21. Vasconcellos MC, Pignatti MG, Pignati WA. Emprego e acidentes de trabalho na indústria frigorífica em áreas de expansão do agronegócio, Mato Grosso, Brasil. Saude soc. 2009; 18(4):662-672.

22. Gomaa NF, El-Derea HB, ElI-Adham E. Hazard analysis and critical point identification at Abiss slaughter house in Alexandria. J Egypt Public Health Assoc 2003; 78(3-4):287-303.

23. Hinrichsen L. Manufacturing technology in the Danish pig slaughter industry. Meat Sci 2010; 84(2):271-275

24. Freitas JD, Galindo GA, Santos EJ, Sarraf Kd, Oliveira JP. Zoonotic brucellosis risk associated with clandestine slaughtered porks. Rev Saude Publica 2001; 35(1):101-102.

25. Brasil. Ministério do Trabalho e Emprego (MTE). Departamento de Segurança e Saúde no Trabalho. Nota Técnica: Medidas para Controle de Riscos Ocupacionais na Indústria de Abate e Processamento de Carnes. Brasília: MTE; 2004.

26. Sarda SE, Ruiz RC, Kirtschig G. Juridical tutelage concerning the health of meat packing workers: public service considerations. Acta Fisiatr 2009; 16(2):59-65.

27. Serranheira F, Uva A, Espírito-Santo J. Risco de LMEMSLT em actividades de abate e desmancha de carnes. Saúde \& Trabalho 2007; 6(1):43-61.

28. Araújo GCD, Gosling M. Gestão de acidentes de trabalho em uma empresa frigorífica: um estudo de caso. Rev Pretexto 2008; 9(1):81-94.

29. Quandt SA, Grzywacz JG, Marin A, Carrillo L, Coates ML, Burke B, Arcury TA. Illnesses and injuries reported by Latino poultry workers in western North Carolina. Am J Ind Med 2006; 49(5):343-351.

30. Johnson ES, Ndetan H. Non-cancer mortality in poultry slaughtering/processing plant workers belonging to a union pension fund. Environ Int 2011; 37(2):322-327.

31. Lachance DH, Lennon VA, Pittock SJ, Tracy JA, Krecke KN, Amrami KK, Poeschla EM, Orenstein R, Scheithauer BW, Sejvar JJ, Holzbauer S, Devries AS, Dyck PJ. An outbreak of neurological autoimmunity with polyradiculoneuropathy in workers exposed to aerosolised porcine neural tissue: a descriptive study. Lancet Neurol 2010; 9(1):55-66.
32. Pacheco JW, Yamanaka HT. Guia técnico ambiental de abates (bovino e suíno). São Paulo: CETESB; 2006.

33. Netto GF, Johnson ES. Mortality in workers in poultry slaughtering/processing plants: the Missouri poultry cohort study. Occup Environ Med 2003; 60(10):784-788.

34. Perdekamp MG, Kneubuehl BP, Ishikawa T, Nadjem H, Kromeier J, Pollak S, Thierauf A. Secondary skull fractures in head wounds inflicted by captive bolt guns: autopsy findings and experimental simulation Int Journal of Legal Medicine 2010; 124(6):605-612.

35. Lander L, Sorock GS, Stentz TL, Eisen EA, Mittleman M, Hauser R, Perry MJ. A case-crossover study of occupational laceration injuries in pork processing: methods and preliminary findings Occup Environ Med 2010; 67(10):686-692

36. Caci C, Perry MJ, Sarock GS, Hauser R, Spanger KJ, Mitteman MA, StentzTL. Laceration among workers at meat packing plants. Am J Ind Med 2005; 47(5):403-410.

37. Coleman GJ, McGregor M, Hemsworth PH, Boyce J, Dowling S. The relationship between beliefs, attitudes and observed behaviours of abattoir personnel in the pig industry. Appl Anim Beh Science 2003; 82(3):189-200.

38. Bongers P, Kremer A, Laak J. Are psychosocial factors, risk factors for symptoms and signs of the shoulder, elbow or hand/wrist?: a review of the epidemiologic literature. Am J Ind Med 2002; 41(5):315-342.

39. Villar-Gómez A, Muñoz X, Culebras M, Morell F, Cruz MJ. Occupational asthma caused by inhalation of surfactant composed of amines. Scand J Work Environ Health 2009; 35(6):475-478.

40. Marquès LI, Lara S, Abós T, Bartolomé B. Occupational rhinitis due to pepsin. J Investig Allergol Clin Immunol 2006; 16(2):136-137.

41. Wenzlawowicz MV, Holleben KV, Bostelmann N. $\mathrm{CO}^{2}$ stunning of broilers and turkey hens. Dtsch Tierarztl Wochenschr 2000; 107(3):116-122.

42. Johnson ES. Cancer mortality in workers employed in cattle, pigs, and sheep slaughtering and processing plants. Environ Int 2011; 37(5):950-959.

43. Johnson ES, Ndetan H, Lo KM. Cancer mortality in poultry slaughtering/processing plant workers belonging to a union pension fund. Environ Res 2010; 110(6):588-594.

44. McLean D, Pearce N. Cancer among meat industry workers. Scand J Work Environ Health 2004; 30(6): 425-437.

45. Fritschi L, Fenwick S, Bulsara M. Mortality and cancer incidence in a cohort of meatworkers. Occup Environ Med 2003; 60(9):E4.

46. Boffetta P, Gridley G, Gustavsson P, Brennan P, Blair A, Ekström AM, Fraumeni JF. Employment as butcher and cancer risk in a record-linkage study from Sweden. Cancer Causes Control 2000; 11(7):627-633.

47. Makita K, Fèvre EM, Waiswa C, Kaboyo W, Eisler MC, Welburn SC. Spatial epidemiology of hospitaldiagnosed brucellosis in Kampala, Uganda. Int $J$ Health Geogr 2011; 10:52. 
48. Mukhtar F. Brucellosis in a high risk occupational group: seroprevalence and analysis of risk factors. J Pak Med Assoc 2010; 60(12):1031-1034.

49. Swai ES, Schoonman L. Human brucellosis: seroprevalence and risk factors related to high risk occupational groups in Tanga Municipality, Tanzania. Zoonoses Public Health 2009; 56(4):183-187.

50. Yoo SJ, Choi YS, Lim HS, Lee K, Park MY, Chu C, Kang YA. Seroprevalence and risk factors of brucellosis among slaughterhouse workers in Korea. $J$ Prev Med Public Health 2009; 42(4):237-242.

51. Mukhtar F, Kokab F. Brucella serology in abattoir workers. J Ayub Med Coll Abbottabad 2008; 20(3):5761.

52. Ramos TR, Pinheiro Junior JW, Moura Sobrinho PA, Santana VL, Guerra NR, Melo LE, Mota RA. Epidemiological aspects of an infection by Brucella abortus in risk occupational groups in the microregion of Araguaína, Tocantins. Braz J Infect Dis 2008; 12(2):133-138.

53. Gonçalves DD, Teles PS, Reis CR, Lopes FMR, Freire RL, Navarro IT, Alves LA, Muller EE, Freitas JC. Seroepidemiology and occupational and environmental variables for leptospirosis, brucellosis and toxoplasmosis in slaughterhouse workers in the Paraná State, Brazil. Rev. Inst. Med. Trop. São Paulo 2006; 48(3):135-140.

54. Rapisarda V, Valentino M, Ravalli P, Fenga C, Duscio D. Occupational brucellosis in slaughtering of sheep and goats: study of five cases from a municipal abattoir in south-eastern Sicily. Med Lav 2005; 96(2):134-141.

55. Karimi A, Alborzi A, Rasooli M, Kadivar MR, Nateghian AR. Prevalence of antibody to Brucella species in butchers, slaughterers and others. East Mediterr Health J 2003; 9(1-2):178-184.

56. El-Ansary EH, Mohammed BA, Hamad AR, Karom AG. Brucellosis among animals and human contacts in eastern Sudan. Saudi Med J 2001; 22(7):577579.

57. Rodríguez Valín ME, Pousa Ortega A, Pons Sánchez C, Larrosa Montañés A, Sánchez Serrano LP, Martínez Navarro F. Brucellosis as occupational disease: study of an outbreak of air-born transmission at a slaughter house. Rev Esp Salud Publica 2001; 75(2):159-169.

58. Dorjee S, Heuer C, Jackson R, West DM, CollinsEmerson JM, Midwinter AC, Ridler AL. Assessment of occupational exposure to leptospirosis in a sheep-only abattoir. Epidemiol Infect 2011; 139(5):797-806.

59. Nájera S, Alvis N, Babilonia D, Alvarez L, Máttar S. Leptospirosis ocupacional en una región del Caribe colombiano. Salud Pública Méx 2005; 47(3):240-244.

60. Babür C, Ozdemir V, Kiliç S, Erol E, Esen B. AntiLeptospira antibodies in slaughterhouse workers in Ankara. Mikrobiyol Bul 2003; 37(2-3):143-150.

61. Delbem ACB, Freitas JC, Bracarense APFRL, Müller EE, Oliveira RC. Leptospirosis in slaughtered sows: serological and histopathological investigation. Braz J Microbiol 2002; 33(2):174-177.
62. Terry J, Trent M, Bartlett M. A cluster of leptospirosis among abattoir workers. Commun Dis Intell 2000; 24(6):158-160.

63. Ma Y, Jin T, Wang L, Yang T, Li L, Zhang L. Study on the behavioral risk of toxoplasma infection in population working in the slaughterhouse. Zhonghua Liu Xing Bing Xue Za Zhi 2002; 23(1):43-45.

64. Alvarado-Esquivel C, Liesenfeld O, Estrada-Martínez S, Félix-Huerta Toxoplasma gondii infection in workers occupationally exposed to raw meat. J. Occup Med 2011; 61(4):265-269.

65. Daguer H, Vicente RT, Costa T, Virmond MP, Hamann W, Amendoeira MRR. Soroprevalência de anticorpos anti-Toxoplasma gondii em bovinos e funcionários de matadouros da microrregião de Pato Branco, Paraná, Brasil. Cienc. Rural 2004; 34(4):1133-1137.

66. Sroka J, Zwoliñski J, Dutkiewicz J. The prevalence of anti-Toxoplasma gondii antibodies among abattoir workers in Lublin. Wiad Parazytol 2003; 49(1):47-55.

67. Milazzo A, Featherstone KB, Hall RG. Q fever vaccine uptake in South Australian meat processors prior to the introduction of the National Q Fever Management Program. Commun Dis Intell 2005; 29(4):400-406.

68. Horio M, Nakamura K, Shimada M. Risk of Toxoplasma gondii infection in slaughterhouse workers in Kitakyushu City. J UOEH 2001; 23(3):233-243.

69. Adesiyun A, Dookeran S, Stewart-Johnson A, Rahaman S, Bissessar S. Frequency of seropositivity for Coxiella burnetii immunoglobulins in livestock and abattoir workers in Trinidad. New Microbiol 2011; 34(2):219-224.

70. Wilson LE, Couper S, Prempeh H, Young D, Pollock KG, Stewart WC, Browning LM, Donaghy M. Investigation of a $\mathrm{Q}$ fever outbreak in a Scottish colocated slaughterhouse and cutting plant. Zoonoses Public Health 2010; 57(7-8):493-498.

71. Tarradas C, Luque I, de Andrés D, Abdel-Aziz Shahein YE, Pons P, González F, Borge C, Perea A. Epidemiological relationship of human and swine Streptococcus suis isolates. J Vet Med B Infect Dis Vet Public Health 2001; 48(5):347-355.

72. Gilroy N, Formica N, Beers M, Egan A, Conaty S, Marmion B. Abattoir-associated Q fever: a Q fever outbreak during a $\mathrm{Q}$ fever vaccination program. Aust N Z J Public Health 2001; 25(4):362-367.

73. Balm MN, Truong HT, Choudhary AS, Robinson GM, Blackmore TK. Streptococcus gallinaceus bacteraemia in an abattoir worker presenting with a febrile illness. J Med Microbiol 2006; 55(7):957-959.

74. Strangmann E, Fröleke H, Kohse KP. Septic shock caused by Streptococcus suis: case report and investigation of a risk group. Int $J$ Hyg Environ Health 2002; 205(5):385-392.

75. Wong PL, Fedder G, Heilmann FG. A man with Campylobacter endocarditis, treatable as Campylobacter fetus following identification. Ned Tijdschr Geneeskd 2003; 147(9):399-403. 
76. Phillips G, Efstratiou A, Tanna A, Beall B, Ferguson J, Roworth M. An outbreak of skin sepsis in abattoir workers caused by an 'unusual' strain of Streptococcus pyogenes. J Med Microbiol 2000; 49(4):371374.

77. Denis M, Chidaine B, Laisney MJ, Kempf I, Rivoal K, Mégraud F, Fravalo P. Comparison of genetic profiles of Campylobacter strains isolated from poultry, pig and Campylobacter human infections in Brittany, France. Pathol Biol 2009; 57(1):23-29.

78. Vulcano A, Angelucci M, Candelori E, Martini V, Patti AM, Mancini C, Santi AL, Calvani A, Casagni L, Lamberti A. HEV prevalence in the general population and among workers at zoonotic risk in Latium Region. Ann Ig. 2007; 19(3):181-186.

79. Logan JM, Burnens A, Linton D, Lawson AJ, Stanley J. Campylobacter lanienae sp. nov., a new species isolated from workers in an abattoir. Int J Syst Evol Microbiol 2000; 50(2):865-872.

80. Masia G, Orrù G, Liciardi M, Desogus G, Coppola RC, Murru V, Argiolas M, Orrù G. Evidence of hepatitis $\mathrm{E}$ virus (HEV) infection in human and pigs in Sardinia, Italy. J Prev Med Hyg 2009; 50(4):227-231.

81. Hoelzer K, Switt AM, Wiedmann M. Animal contact as a source of human non-typhoidal salmonellosis. Veterinary Research 2011; 42(1):34.

82. Jary C. Hepatitis E and meat carcasses. Br J Gen Pract 2005; 55(516):557-558.

83. Chew MH, Arguin PM, Shay DK, Goh KT, Rollin PE, Shieh WJ, Zaki SR, Rota PA, Ling AE, Ksiazek TG, Chew SK, Anderson LJ. Risk factors for Nipah virus infection among abattoir workers in Singapore. $J$ Infect Dis 2000; 181(5):1760-1763.

84. Ola SO, Otegbayo JA, Yakubu A, Odaibo GN, Olaleye DO. Risk of hepatitis B virus in the slaughter house. Trop Doct 2008; 38(4):249-250.

85. Biffa D, Bogale A, Skjerve E. Diagnostic efficiency of abattoir meat inspection service in Ethiopia to detect carcasses infected with Mycobacterium bovis: Implications for public health. BMC Public Health 2010; 10:462.

86. Maslen MM. Human cases of cattle ringworm due to Trichophyton verrucosum in Victoria, Australia. Australas J Dermatol. 2000; 41(2):90-94.

87. Bianli X, Zaolin C, Qingxia H, Hui L. Epidemiological survey of Trichinella infection in some areas of Henan province. Parasite. 2001; 8(2):S71-S73.

88. Williams RJ, Al-Busaidy S, Mehta FR, Maupin GO, Wagoner KD, Al-Awaidy S, Suleiman AJ, Khan AS, Peters CJ, Ksiazek TG. Crimean-congo haemorrhagic fever: a seroepidemiological and tick survey in the Sultanate of Oman. Trop Med Int Health 2000; 5(2):99-106.

89. Ciçek M, Körkoca H, Gül A. Investigation of Cryptosporidium sp. in workers of the Van municipality slaughterhouse and in slaughtered animals. Turkiye Parazitol Derg 2008; 32(1):8-11.

90. Cocco PL, Caperna A, Vinci F. Occupational risk factors for the sporadic form of Creutzfeldt-Jakob disease. Med Lav 2003; 94(4):353-363.
91. Ríos L, Alvarez G, Blair S. Serological and parasitological study and report of the first case of human babesiosis in Colombia. Rev. Soc. Bras. Med. Trop. 2003; 36(4):493-498.

92. Deutz A, Fuchs K, Auer H, Kerbl U, Aspöck H, Köfer J. Toxocara-infestations in Austria: a study on the risk of infection of farmers, slaughterhouse staff, hunters and veterinarians. Parasitol Res. 2005; 97(5):390-394.

93. Cardoso TAO, Silva I. Biossegurança no manejo de animais. In: Cardoso TAO, Navarro MBMA, organizadores. A Ciência entre "Bichos" e "Grilos": reflexões e ações da Biossegurança nas pesquisas com animais. São Paulo: Hucitec; 2007. p.229-257.

94. Centers for Disease Control and Prevention (CDC). Biosafety in microbiological and biomedical laboratories. Atlanta: CDC; 2009.

95. Acha PN, Szyfres B. Zoonosis y Enfermedades Transmisibles Comunes al Hombre y a los Animales. Washington: OPAS; 2003.

96. Hinds W. Aerosol Technology: properties, behavior and measurement of airborne particles. New York: Willey Interscience Publication; 1998.

97. National Research Council. Biosafety in the laboratory: prudent practices for the handling and disposal of infectious materials. Washington: National Academy Press; 1989.

98. Sahani M, Parashar UD, Ali R, Das P, Lye MS, Isa MM, Arif MT, Ksiazek TG, Sivamoorthy M. Nipah virus infection among abattoir workers in Malaysia, 1998-1999. Int J Epidemiol 2001; 30(5):1017-1020.

99. Cardoso TAO, Navarro MBMA, Neto CC, Moreira JM. Health surveillance, biosafety and emergence and re-emergence of infectious diseases in Brazil. Brz J Infect Dis 2010; 14(5):526-535.

Artigo apresentado em 15/05/2012

Aprovado em 01/07/2012

Versão final apresentada em 08/07/2012 
